\title{
AVALIAÇÃO DE DESEMPENHO NA CONTABILIDADE GERENCIAL: APLICAÇÃO DO PROCESSO PROKNOW-C PARA GERAÇÃO DE CONHECIMENTO
}

\section{RESUMO}

A presente pesquisa teve como objetivo analisar as características das pesquisas científicas internacionais do fragmento da literatura sobre a utilização da Avaliação de Desempenho (AD) na Contabilidade Gerencial para a geração de conhecimento e identificação de lacunas e de possibilidades de pesquisas futuras. Para isso, esta pesquisa, com abordagem qualitativa, utilizou a ferramenta ProKnow-C para a seleção do Portfólio Bibliográfico (PB) e análise das características de suas publicações. A pesquisa resultou em dezesseis artigos alinhados ao tema, que compuseram o PB e tiveram estes resultados: o periódico Transformations in Business and Economics é o que possui maior número de publicações do PB; dos 21 autores dos artigos do PB, o autor Md. Mostaque Hussain possui maior número de publicações, quatro; a teoria da contingência foi a teoria mais utilizada pelos autores quanto ao alicerce da $\mathrm{AD}$; e vários estudos utilizaram o caminho da $\mathrm{AD}$ no sentido de tornar as métricas mais dinâmicas. Com base no estudo bibliográfico, foram identificadas as seguintes lacunas de pesquisa: inexistência de pesquisas que tenham como foco a teoria da agência e a teoria dos stakeholders; e inexistência de pesquisas tendo como foco o caminho da AD ampliado para os stakeholders. Para promover avanços na área, observa-se a necessidade de estudos que englobem os interesses dos stakeholders pela utilização do sistema de avaliação de desempenho, de forma que sejam ampliadas as informações a serem geradas por esse sistema.

Palavras-chave: Contabilidade Gerencial; Avaliação de Desempenho; ProKnow-C.

\section{PERFORMANCE EVALUATION IN MANAGEMENT ACCOUNTING: APLICCATION OF PROCESS PROKNOW-C FOR KNOWLEDGE GENERATION}

\begin{abstract}
This research aimed to analyze the characteristics of international scientific research about the literature fragment on the use of Performance Evaluation (PE) in Management Accounting for the knowledge generation and identifying gaps and future research possibilities. To this end, this research with qualitative approach used ProKnow-C tool for selecting the Bibliographical Portfolio (PB) and analysis of the characteristics of its publications. The research resulted in sixteen articles aligned to the subject, who composed the PB and had these results: the journal Transformations in Business and Economics is the one with the highest number of publications portfolio; of the 21 authors, of the articles of the PB, the author Mostaque Md Hussain has largest number of publications, four; the contingency theory was the most used by the authors as the foundation of the Performance Evaluation and; several studies have used the Performance Evaluation path towards becoming the metrics most dynamic. Based on the literature study, the following research gaps were identified: lack of research that focus on the agency theory and the theory of stakeholders and lack of research focusing on the PE path extended to the stakeholders. To promote advances in the field, there is a need for studies that encompass the interests of stakeholders for the use of performance appraisal system, so that they are enlarged the information to be generated by this system.
\end{abstract}

Keywords: Management Accounting; Performance Evaluation; ProKnow-C. 


\section{EVALUACIÓN DEL DESEMPEÑO EN LA CONTABILIDAD DE GESTIÓN: PROCESO DE SOLICITUD PROKNOW-C PARA LA GENERACIÓN DE CONOCIMIENTO}

\section{RESUMEN}

Este estudio tuvo como objetivo analizar las características de la literatura internacional fragmento de la investigación científica sobre el uso de la Evaluación del Desempeño (AD) en la Contabilidad de Gestión para la generación de conocimiento y la identificación de las deficiencias y las posibilidades futuras de investigación. Con este fin, esta investigación con un enfoque cualitativo, utilizó la herramienta ProKnow-C para la selección de la cartera Bibliográfico (PB) y el análisis de las características de sus publicaciones. La investigación dio lugar a dieciséis artículos alineados con el tema, que compuso la PB y tuvo los siguientes resultados: la revista Transformaciones en Negocios y Economía es el que tiene el mayor número de publicaciones PB; . De los 21 autores de los artículos de la CP, el autor Mostaque Md Hussain tiene el mayor número de publicaciones, cuatro; la teoría de la contingencia era la teoría más utilizada por los autores como el fundamento de la EA; y varios estudios han utilizado la ruta de AD hacia la fabricación de las métricas más dinámicos. Con base en el estudio de la literatura, se identificaron las siguientes lagunas de investigación: la falta de investigación que se centran en la teoría de la agencia y la teoría de las partes interesadas; y la falta de investigación que se centra en el camino AD extendido a las partes interesadas. Para promover avances en el campo, hay una necesidad de estudios que abarcan los intereses de las partes interesadas para el uso del sistema de evaluación del desempeño, de manera que se amplían la información que serán generados por este sistema.

Palabras clave: Contabilidad de Gestión; Evaluación del desempeño; ProKnow-C.

\footnotetext{
1 Mestranda em Contabilidade pela Universidade Federal de Santa Catarina - UFSC. Brasil. E-mail: fabiiana_fs@hotmail.com

2 Doutora em Engenharia de Produção pela Universidade Federal de Santa Catarina - UFSC. Professora da Universidade Federal de Santa Catarina - UFSC. Brasil. E-mail: sensslin@ gmail.com

3 Doutora em Engenharia de Produção pela Universidade Federal de Santa Catarina - UFSC. Professora da Universidade Federal de Santa Catarina - UFSC. Brasil. E-mail: valdirene.gasparetto@ufsc.br
} 


\section{INTRODUÇÃ̃O}

Com o propósito de buscar alinhamento dos objetivos da empresa à sua estratégia, há diversas práticas gerenciais, sendo uma delas a Avaliação de Desempenho (AD) por meio da qual as empresas fazem medições de acordo com as medidas estabelecidas e têm informações relacionadas ao seu desempenho interno ou externo (Abdel-Kader, \& Luther, 2006; Nita, 2008; Neely, 1999). Com as informações geradas pela $\mathrm{AD}$, os gestores podem analisar o desempenho de centros de responsabilidade ou unidades de negócios e verificar se os esforços estão sendo direcionados para o alcance dos objetivos da empresa e para assegurar a implementação da estratégia empresarial (Hussain, \& Gunasekaran, 2002).

Quando as empresas iniciaram a prática da avaliação de desempenho, esta era baseada na Contabilidade tradicional, com medidas principalmente voltadas ao desempenho financeiro (Valmorbida, \& Ensslin, 2016; Yadav, Sushil, \& Sagar, 2014; Bititci, Garengo, Dörfler \& Nudurupati, 2012; Nudurupati, Bititci, Kumar, \& Chan, 2011; Otley, 2001; Neely, 1999). No entanto, em um mercado dinâmico, as mudanças fizeram com que a atividade de $\mathrm{AD}$ se tornasse mais presente nas empresas e com enfoque mais ligado às estratégias empresariais (Yadav et al., 2014; Otley, 2001). A partir daí, os sistemas de avaliação de desempenho passaram a contar também com medidas de avaliação com enfoque não financeiro (Hussain, 2003; Hussain, 2005; Hussain, \& Gunasekaran, 2002; Joshi, 2001).

Ao longo das décadas, vários sistemas de avaliação de desempenho foram desenvolvidos (Neely, Gregory, \& Platts, 1995), mas nem sempre foram utilizados de maneira adequada ao propósito que os gestores esperavam, uma vez que muitos acreditam que a utilização de métricas prontas garante o sucesso do desempenho da organização, sem levar em consideração as suas especificidades (Joshi, Bremser, Deshmukh, \& Gumar, 2011; Kihn, 2010; Nita, 2008; Odar, Kavčič, \& Jerman, 2012; Otley, 2001). Cumpre observar que a seleção, ou a construção, do sistema de avaliação de desempenho deve permitir a incorporação de métricas alinhadas aos objetivos e à estratégia da empresa (Valmorbida, \& Ensslin, 2016). Isso possibilitará que o resultado desejado seja alcançado. Para isso, os gestores devem identificar e evidenciar as características, a cultura e as estratégias da organização a fim de identificar quais métricas podem promover o alcance das metas estabelecidas (Henri, 2010; Hussain, 2003; Nita, 2008; Odar et al., 2012; Otley, 2001).

Nesse contexto, o intuito do presente estudo é responder à seguinte pergunta de pesquisa: Como a literatura sobre a utilização da avaliação de desempenho na contabilidade gerencial, por meio das percepções e do conhecimento resultantes de sua análise, pode ser sintetizada em contribuições para evolução científica desse ramo do conhecimento? Com a intenção de responder à questão-problema, tem-se como objetivo analisar as características das pesquisas científicas internacionais relacionadas ao fragmento de literatura sobre a utilização da avaliação de desempenho na contabilidade gerencial, tendo como propósito a geração de conhecimento e identificação de lacunas para o apontamento de possibilidade de pesquisas futuras. Para atingir esse objetivo, devido à perspectiva construtivista do instrumento Knowledge Development Process-Constructivist (ProKnow-C) e por ser um processo estruturado para seleção e análise da literatura, este foi selecionado para orientar os procedimentos dos autores.

A presente pesquisa justifica-se dada a sua importância, originalidade e viabilidade (Castro, 1977). Este estudo gera uma síntese de diretrizes para novas pesquisas por meio da identificação e análise das características relacionadas às publicações do fragmento de literatura pesquisado e do conhecimento gerado com análise das pesquisas selecionadas. Considera-se relevante por não ter sido encontrado, na literatura consultada, estudo que realizasse a análise: (i) das teorias com base no proposto por Franco-Santos, Lucianetti e Bourne (2012) e por Donaldson e Preston (1995); (ii) em qual/quais do(s) caminho(s) da avaliação de desempenho os estudos se afiliaram, conforme sugerido por Srimai, Radford e Wright (2011); e, (iii) em contexto similar ao explorado na presente pesquisa. Visto que os artigos utilizados no presente estudo foram selecionados no portal de periódicos da CAPES e que os pesquisadores se encontram disponíveis e empenhados na coleta, leitura e análise dos dados, a pesquisa torna-se viável.

\section{REFERENCIAL TEÓRICO}

Esta seção apresenta (i) à noção de avaliação de desempenho adotada pelos autores com base nas definições identificadas na literatura, bem como a evolução dos sistemas de avaliação de desempenho; e (ii) à noção de avaliação de desempenho e sua utilização na contabilidade gerencial.

\subsection{Avaliação de Desempenho}

Embora o termo Avaliação de Desempenho (AD) seja amplamente utilizado, encontra-se na literatura várias denominações utilizadas como sinônimos, bem como várias e distintas noções/conceitos (Valmorbida, \& Ensslin, 2016). Sendo assim, iniciamos esta seção esclarecendo o que entendemos por $\mathrm{AD}$, por meio da apresentação evolutiva de conceitos complementares da literatura. Na sequência, apresenta-se a evolução dos sistemas de avaliação de desempenho.

Segundo Roy (1990; 1993), a avaliação de desempenho é uma vertente da Pesquisa Operacional 
(PO) que pode ser utilizada por várias áreas do conhecimento, sendo que, a partir de 1970, dividiu-se em duas correntes científicas 'marcadas' pela diferença de atitude do especialista/facilitador: uma focada na busca de informações para Tomada de Decisão e outra na construção de informações para Ajuda/Apoio à Decisão. Em linhas sucintas, a vertente da tomada de decisão devota estudos para a atividade de mensuração, e a vertente apoio à decisão devota estudos para a atividade de gestão, que inclui a mensuração.

Dentre os conceitos seminais, tem-se o formulado por Neely et al. (1995, p. 1229) que definem um Sistema de Avaliação de Desempenho "como um conjunto de métricas utilizado para quantificar a eficiência e/ou eficácia das ações". Direcionando à vertente do apoio à decisão, Melnyk, Bititci, Platts, Tobias e Andersen (2014) complementam a definição acima afirmando que somente a mensuração não é suficiente em um sistema de avaliação de desempenho, faz-se necessária a atividade de gestão. Para esses autores um Sistema de Avaliação de Desempenho é composto por dois componentes: mensuração e gestão (Melnyk et al., 2014, p. 175). Nesse contexto, Dutra, Ripoll-Feliu, Fillol, Ensslin e Ensslin (2015, p. 246) definem AD como "o processo para construir conhecimento no decisor, sobre um contexto específico que deseja avaliar, por meio de atividades que identificam, organizam, mensuram, ordinal e cardinalmente, os objetivos que permitem ao decisor identificar as consequências das ações para melhoria no desempenho" (tradução nossa). Nesse conceito, percebe-se, claramente, a presença dos componentes mensuração e gestão, adicionados à filosofia da abordagem construtivista (Roy,1993) - gerar conhecimento no decisor - que leva ao entendimento da AD para fins internos e externos.

Quanto ao que se entende por AD, passa-se, a seguir, a uma sucinta apresentação da evolução dos sistemas de avaliação de desempenho, ao longo dos anos, em termos da natureza de suas medidas de desempenho e dos caminhos sob os quais a AD passou a ser entendida e utilizada, a fim de embasar o leitor quando da discussão de utilizar a noção de $\mathrm{AD}$ pela Contabilidade Gerencial.

Inicialmente, os sistemas de avaliação de desempenho eram compostos por medidas de desempenho com foco financeiro, baseadas no sistema de controle gerencial (Ghalayini, \& Noble, 1996). Ao longo do tempo, surgiu a necessidade de serem incorporadas outras medidas; sendo assim, os sistemas de avaliação de desempenho contemporâneos utilizam medidas de desempenho financeiras e incorporam medidas de desempenho não financeiras relacionadas com a estratégia da empresa (Franco-Santos et al., 2012).

Essa necessidade de repensar a natureza das medidas de desempenho é motivada pela função que se espera que o Sistema de Avaliação de Desempenho exerça na organização. Dentre as funções, FrancoSantos, Kennerley, Micheli, Martinez, Mason, Marr,
Gray e Neely (2007, p. 797) apontam cinco, quais sejam: a "avaliação de desempenho" em seu papel elementar de mensurar o desempenho; a "gestão estratégica" em seu papel de planejar, criar ações alinhadas ao foco estratégico da organização; a "comunicação" interna e externa em seu papel de informar o alinhamento/distanciamento com as metas estabelecidas e com desempenhos benchmarking; a de "influenciar o comportamento" em seu papel de agregar/desagregar os stakeholders; e a de "aprendizado e melhoria" em seu papel de geradora de conhecimento e fomentadora de ações de aperfeiçoamento.

Embora Franco-Santos et al. (2007) mencionem que essas são funções suficientes e necessárias em um Sistema de Avaliação de Desempenho, nem sempre as organizações ao construírem ou selecionarem um sistema demandam todas as funções. Com base na pesquisa de Srimai et al. (2011), é possível comprovar tal afirmação. Srimai et al. (2011, p. 662) analisaram trabalhos publicados por pesquisadores americanos e constataram que o uso da avaliação de desempenho está associado a "caminhos evolutivos" sob os quais a AD passou a ser entendida, sendo possível seguir um, dois, três ou quatro caminhos simultaneamente. São estes os processos de transição da avaliação de desempenho organizacional: (i) do contexto operacional para a implementação integrada à estratégia organizacional; (ii) como instrumento de implementação da estratégia organizacional para instrumento de gestão estratégica; (iii) como sistema estático para um sistema dinâmico, em função das demandas do ambiente interno e externo; e, (iv) que tem por base apenas interesses internos ligados aos acionistas para a utilização da avaliação considerando os stakeholders.

\subsection{Utilização da Avaliação de Desempenho na Contabilidade Gerencial}

Controle de gestão é definido por Anthony e Govindarajan (2004, apud Nita, 2008, p. 55) como sendo "o processo pelo qual os gerentes influenciam outros membros da organização para implementar as estratégias". Embora Otley (2001) concorde com esta função argumenta que os contadores gerenciais estão envolvidos com a estratégia em termos de seu entendimento; entretanto, pouca atenção é direcionada no processo de fazer a estratégia se tornar real.

Uma das formas de fazer com que todos os envolvidos busquem os mesmos resultados dentro da organização é por meio das medidas de avaliação de desempenho. Dessa forma, segundo Otley (2001) os sistemas de avaliação de desempenho têm grande impacto sobre as ações dos contadores gerenciais.

Mohamed e Hussain (2005) citam que o sistema de avaliação de desempenho será mais eficiente e eficaz quando for utilizado de forma mais ampla e possuir flexibilidade, passando por alterações sempre que necessário para se adequar a mudanças de 
ciclo de vida, no ambiente externo, na missão e estratégia do negócio, etc.

Quanto maior o nível de incerteza do mercado, maior o impacto da revisão periódica de indicadores de desempenho em relação ao desempenho organizacional, dado que o mercado se torna mais dinâmico e os gestores lidam com processos mais complexos e instáveis (Miller, 1988 apud Henri, 2010).

Hall (2008) diz que os indivíduos irão executar suas tarefas de forma adequada somente se tiverem informações suficientes para tal. Nesse sentido, os gestores só poderão gerenciar os negócios se for possível obter informações suficientes com base no sistema de avaliação de desempenho. Assim, o mesmo autor cita a importância de um sistema de AD dinâmico e abrangente, que demonstre informações relevantes que estejam integradas com toda a estratégia empresarial (Hall, 2008).

Segundo Otley (2001), a utilização de medidas inadequadas de desempenho pode levar a atitudes equivocadas por parte dos gestores, gerando um comportamento equivocado, dadas as informações obtidas, considerando um aparente bom desempenho.

\section{METODOLOGIA DA PESQUISA}

Esta seção apresenta o instrumento de intervenção selecionado para o alcance do objetivo desta pesquisa - Knowledge Development ProcessConstructivist (ProKnow-C) -, bem como descreve os procedimentos para coleta e análise dos dados.

\subsection{Instrumento de pesquisa: Knowledge Development Process-Constructivist}

A presente pesquisa utiliza o instrumento Knowledge Development Process-Constructivist (ProKnow-C) desenvolvida por pesquisadores do LabMCDA-UFSC para seleção e análise do Portfólio Bibliográfico (PB) referente ao fragmento da literatura (Valmorbida, \& Ensslin, 2016; Dutra et al., 2015; Kruger, Petri, Ensslin, \& Matos, 2015; Ensslin, Ensslin, Imlau, \& Chaves, 2014; Ensslin, Ensslin, \& Pinto, 2013; Waiczyk, \& Ensslin, 2013).

O ProKnow-C é informado pela base filosófica do construtivismo. Dessa maneira, objetiva a construção de conhecimento, inicialmente, nos pesquisadores e, posteriormente, por meio da transmissão dos conhecimentos adquiridos tangibilizado nas análises, críticas e contribuições da pesquisa para o conhecimento científico apontadas nesta pesquisa (Dutra et al., 2015).

A Figura 1 mostra as fases do processo de operacionalização da ferramenta utilizada, que se constitui de quatro etapas.

Figura 1 - Etapas do ProKnow-C

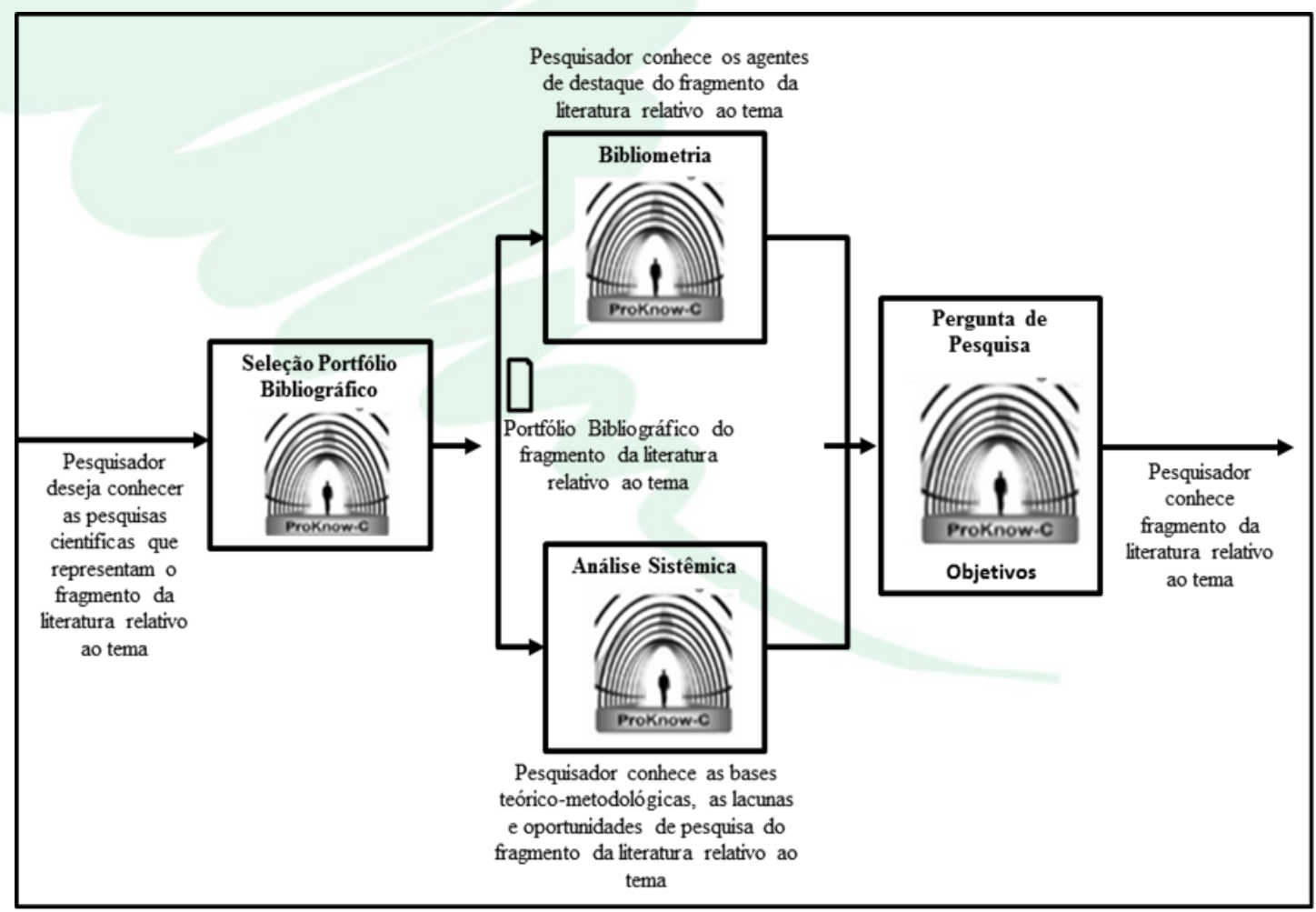

Fonte: Extraído de Valmorbida e Ensslin (2015, p. 7. Adaptado de Ensslin et al., 2010). 
Nesta pesquisa, utilizaram-se apenas as duas primeiras etapas do processo: Seleção do Portfólio Bibliográfico e Análise Bibliométrica.

\subsection{Procedimento para coleta de dados}

Para seleção do PB (Etapa 1) estas três subetapas necessitam ser desenvolvidas: (i) seleção do Banco de Artigos Bruto; (ii) filtragem do Banco de Artigos; e, (iii) teste de representatividade do PB (Dutra et al., 2015; Waiczyk, \& Ensslin, 2013). A Figura 2 demonstra a operacionalização das duas primeiras subetapas que culminaram com a obtenção do Portfólio Bibliográfico primário.

Vale salientar que a subetapa (ii) - filtragem do Banco de Artigos - foi facilitada pelo software
Endnote X7 para exclusão das publicações e pelo software Zotero para identificação das citações dos artigos (reconhecimento científico). Após a obtenção do portfólio primário, foi feita a análise de todas referências contidas nas pesquisas selecionadas a fim de identificar o alinhamento com o tema de pesquisa. Essa análise consiste no teste de representatividade. Nessa etapa, dois artigos foram incorporados ao Portfólio Bibliográfico após a análise do alinhamento integral ao fragmento da literatura pesquisado. Dessa forma, o Portfólio Bibliográfico é composto de 16 artigos científicos. A coleta dos dados aconteceu entre os dias 21 e 22 de março de 2015 com a delimitação temporal de 2000 a 2015.

Figura 2 - Processo para obtenção do Portfólio Bibliográfico primário

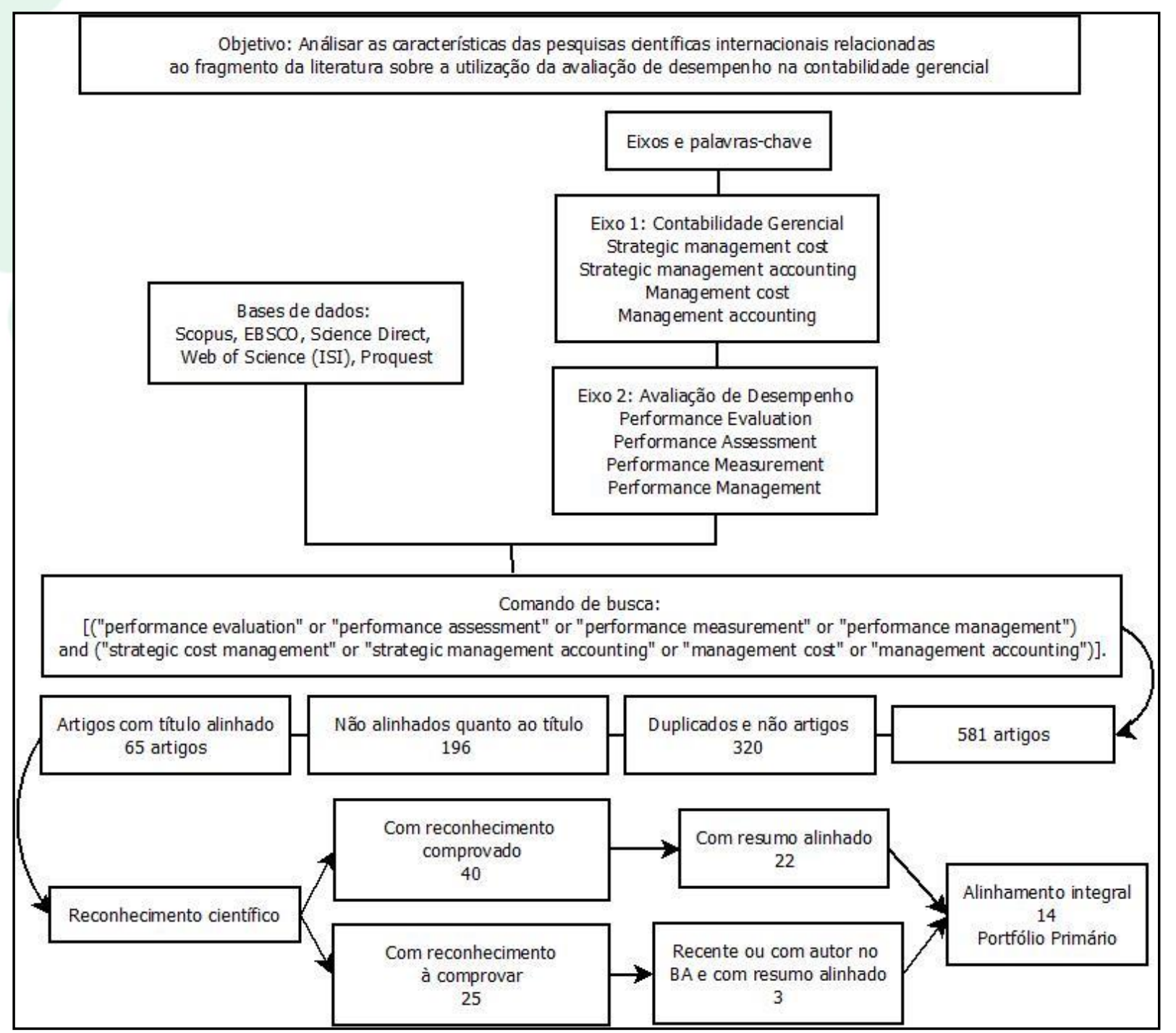

Fonte: Elaborada pelos autores. 
Cumpre observar que, para a validação dos procedimentos e confiabilidade dos resultados, foram utilizadas duas estratégias propostas por Creswell (2014): a metodologia de "member checking", um dos autores da pesquisa, especialista na ferramenta utilizada, realizou a conferência dos processos realizados, garantindo a validade dos resultados apresentados; e a de "auditor externo", um membro externo à pesquisa, pesquisador da área de Contabilidade Gerencial, analisou os procedimentos realizados e aferiu que o Portfólio Bibliográfico selecionado, com base nas delimitações dos pesquisadores, represente o fragmento da literatura relacionado à utilização da avaliação de desempenho pela contabilidade gerencial. Considera-se que a confiabilidade do estudo se dá pela descrição detalhada dos procedimentos metodológicos realizados pelos pesquisadores, permitindo que outros pesquisadores possam replicar o estudo realizado (Creswell, 2014; Yin, 2009).

\subsection{Procedimento de análise dos dados}

Após a seleção do Portfólio Bibliográfico, passa-se à segunda etapa, qual seja, a Análise
Bibliométrica das características dos 16 artigos do PB. As características a serem investigadas neste estudo são: (i) ano de publicação dos artigos; (ii) periódicos que mais têm dedicado espaço para o tema; (iii) artigos relevantes; (iv) quem é/são o(s) autor(es) mais prolífero(s) com trajetória nessa área de conhecimento; (v) teorias em que os processos de avaliação de desempenho estão alicerçados; e, (vi) os "caminhos" sob os quais a avaliação de desempenho dos estudos passou a ser entendida.

As características (i), (ii), (iii) e (iv) serão identificadas pela contagem de ocorrência nos artigos do PB e, na sequência, a interpretação dessa informação será apresentada. Já o procedimento para identificação e análise das características (v) e (iv) é apresentado nas Figuras 3 e 4.

Para fins de conceituação das teorias analisadas na pesquisa, foram utilizadas as definições e teorias elucidadas por Franco-Santos et al. (2012): agência, contingência, visão baseada em recursos, cognitiva e de processamento de informações, definição de metas. Além disso, foi considerada também a teoria dos stakeholders, utilizando a conceituação de Donaldson e Preston (1995). 
Avaliação de Desempenho na Contabilidade Gerencial: Aplicação do Processo Proknow-C para Geração de

Figura 3 - Protocolo de análise referente às teorias subjacentes à avaliação de desempenho

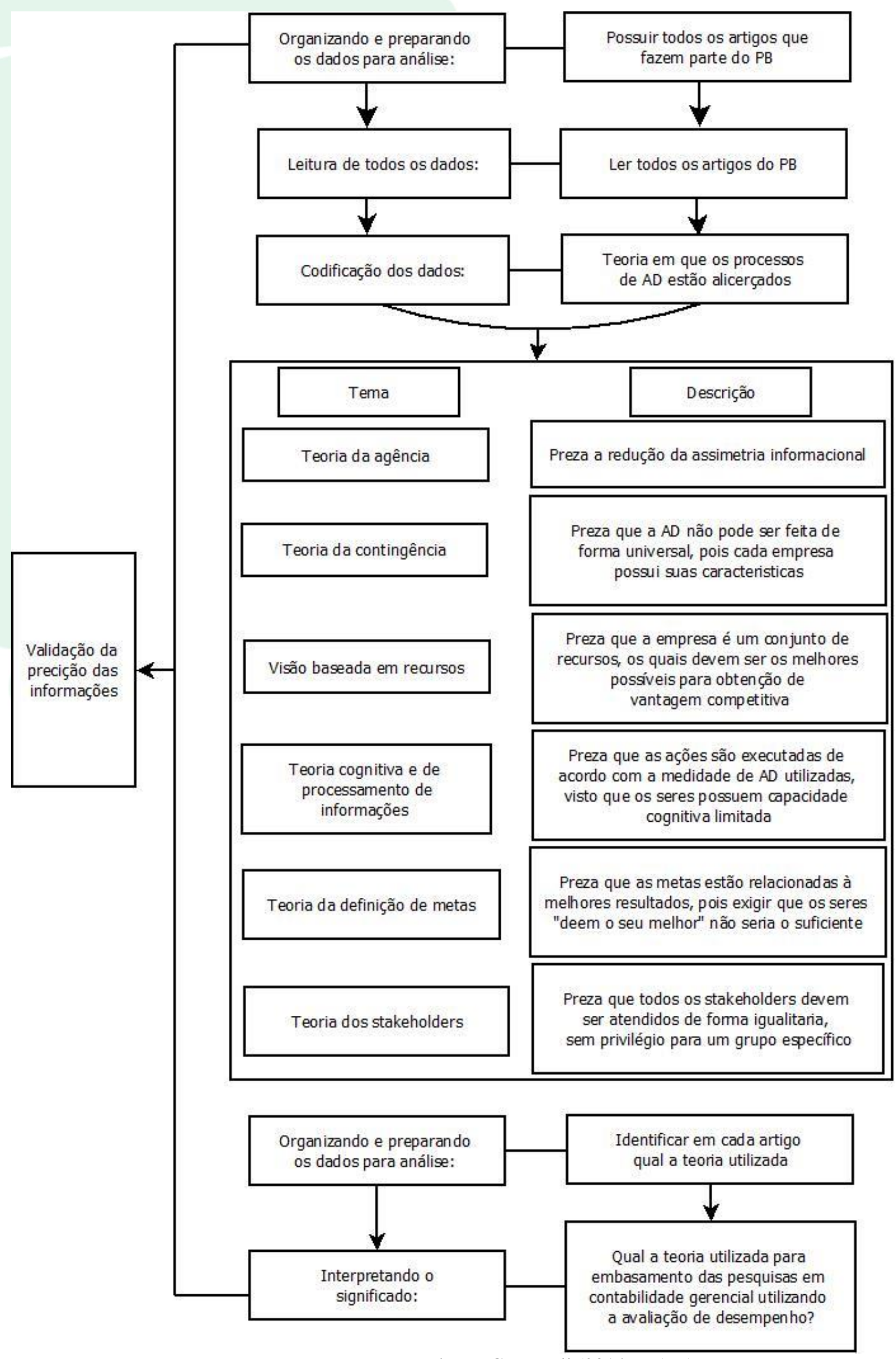

Fonte: Baseado em Cresswell (2014, p. 196). 
Avaliação de Desempenho na Contabilidade Gerencial: Aplicação do Processo Proknow-C para Geração de Conhecimento

A Figura 4 apresenta o protocolo de análise referente aos caminhos da Avaliação de Desempenho (AD).

Figura 4 - Protocolo de análise dos caminhos de AD

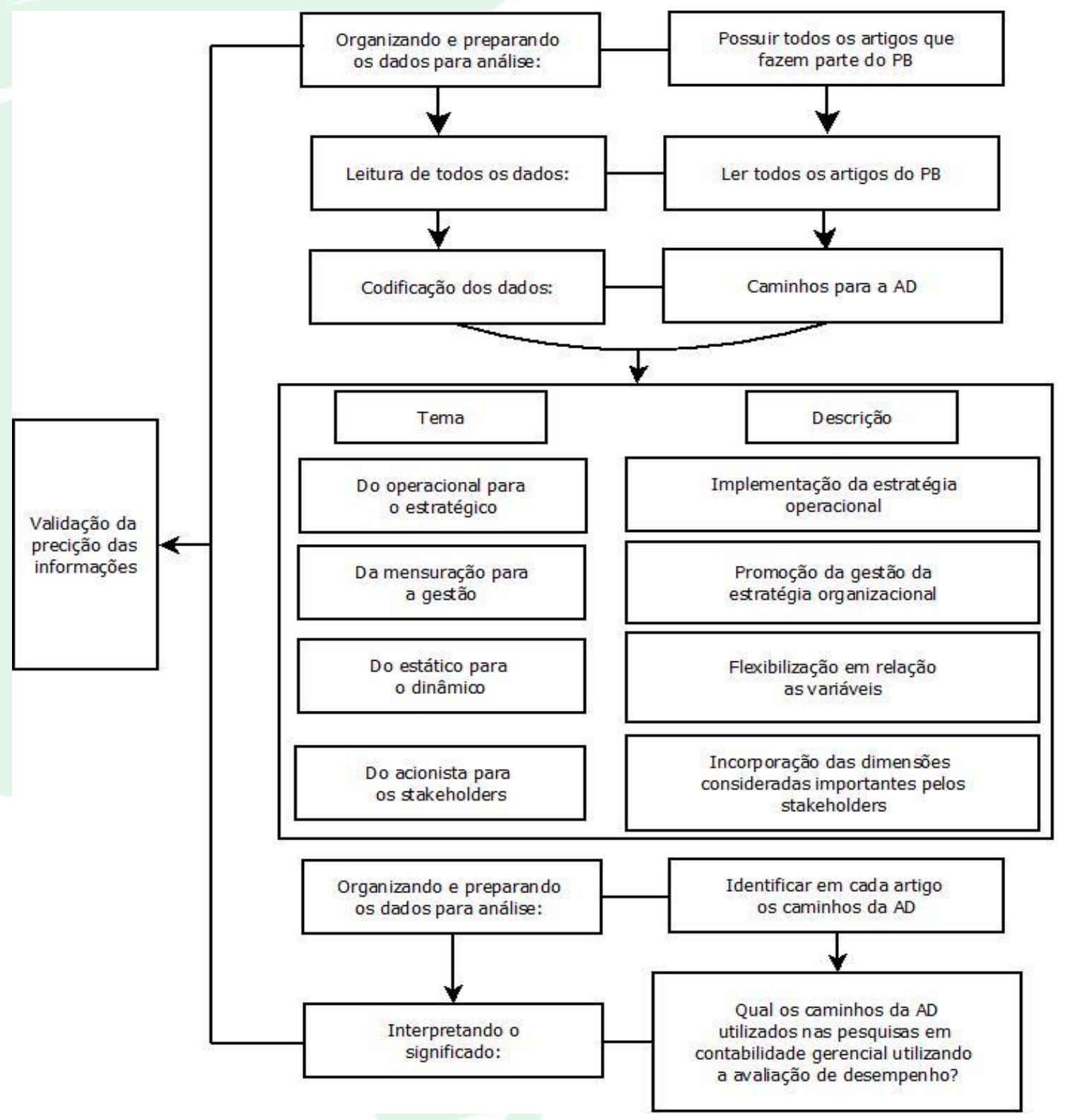

Fonte: Adaptado de Dutra et al. (2015, p. 249), baseada em Cresswell (2014, p. 196).

Como base para os "caminhos da Avaliação de Desempenho", foi utilizada proposta de Srimai et al. (2011 apud Dutra et al., 2015).

\section{RESULTADOS DA BIBLIOMETRIA}

Este tópico apresenta a análise das características dos artigos constantes no PB e de suas referências bibliográficas. Os resultados das análises estão diretamente ligados às escolhas realizadas pelos autores com a utilização da ferramenta ProKnow-C. Dessa forma, a ausência ou a inclusão de um periódico, artigo ou autor está ligada aos parâmetros definidos pelos pesquisadores.

\subsection{Ano de publicação dos artigos}

A Figura 5 apresenta a quantidade de artigos publicados por ano. 
Figura 5 - Publicações por ano

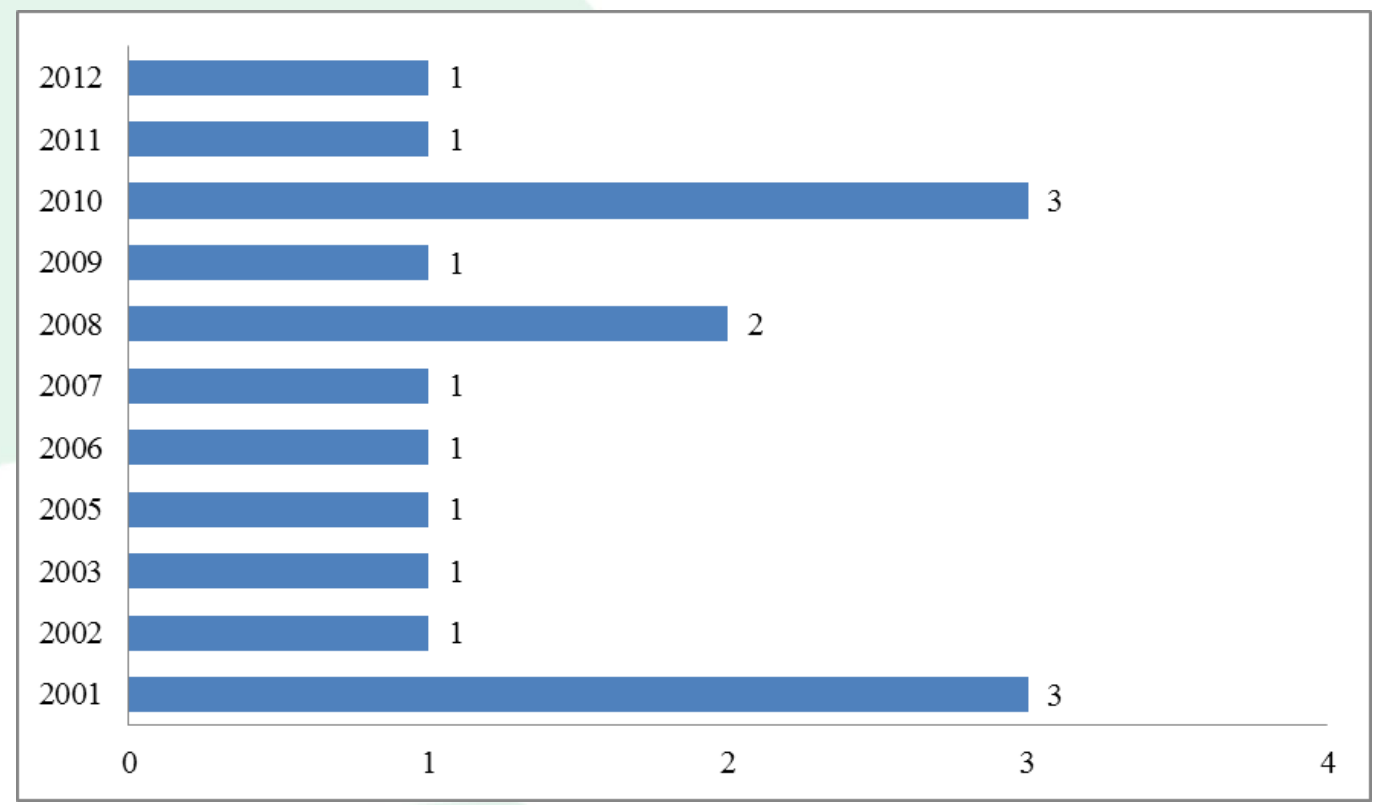

Fonte: Elaborada pelos autores.

Observa-se que não houve um ano, nesse período, que tenha apresentado maior destaque, no entanto os anos de 2001 e 2010 apresentaram um número maior de publicações, três em cada ano. Vale salientar que muitas pesquisas foram realizadas em períodos anteriores, porém elas não se encontram neste trabalho devido à delimitação temporal. Isso pode explicar a pouca representatividade de pesquisas por ano no período selecionado.

Além disso, observa-se a inexistência de pesquisa recentes, dado que a última pesquisa identificada foi realizada no ano de 2012.

\subsection{Periódicos mais relevantes no Portfólio Bibliográfico e nas suas referências}

A Figura 6 demonstra a análise das publicações por periódico. $\mathrm{O}$ periódico Transformations in Business and Economics foi o que apresentou maior representatividade $(12,5 \%)$, tendo duas publicações no PB. Assim, 87,5\% do PB foram publicações em periódicos distintos.

$\mathrm{O}$

periódico com maior representatividade no $\mathrm{PB}$ não é específico da área ou com ligação direta ao tema pesquisado, contudo, por estar ligado à economia de forma geral e suas transformações, aceita publicações na área pesquisada. 
Avaliação de Desempenho na Contabilidade Gerencial: Aplicação do Processo Proknow-C para Geração de

Figura 6 - Periódicos relevantes do PB

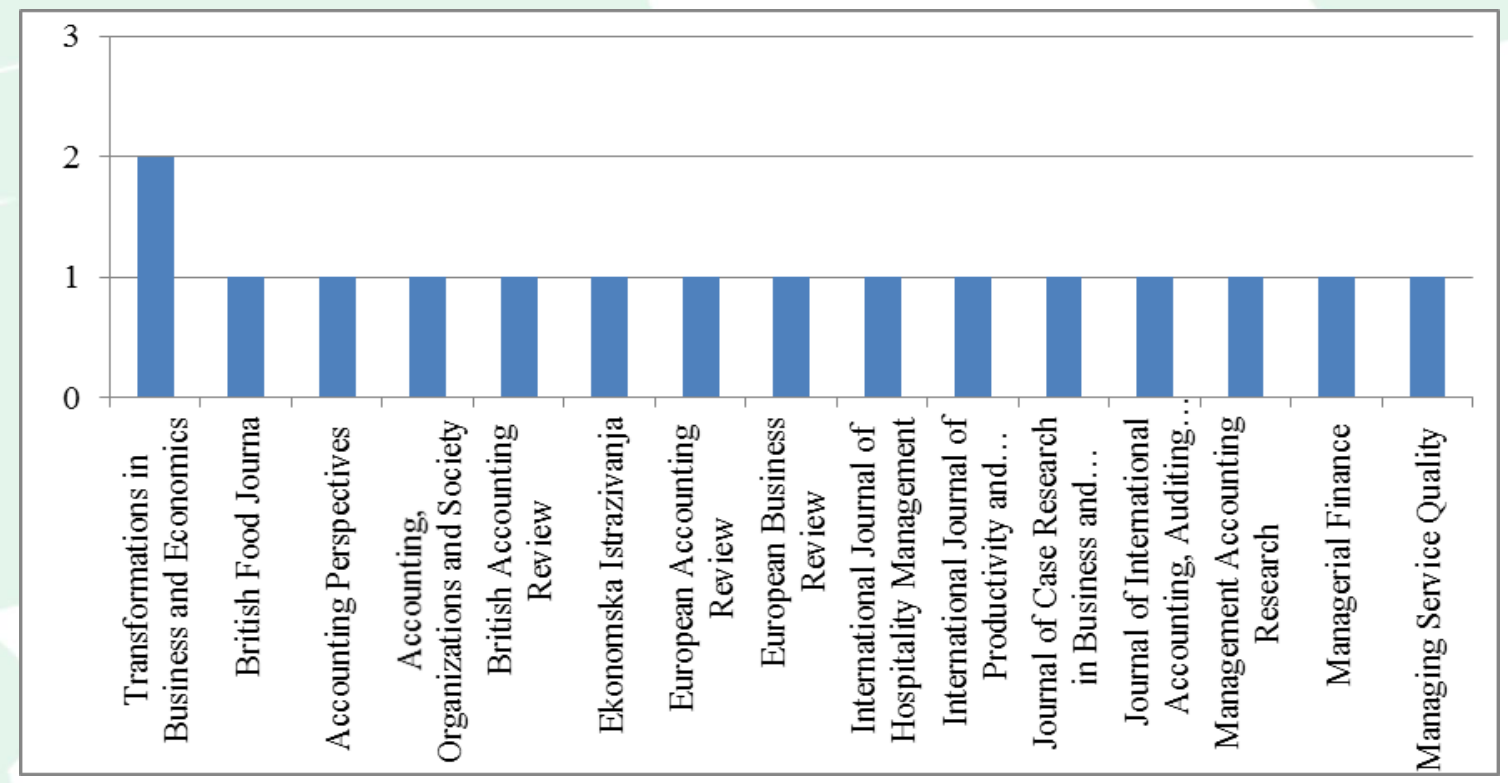

Fonte: Elaborado pelos autores.

A identificação de periódicos mais relevantes por meio da análise das referências bibliográficas do PB foi feita sem a utilização de software e realizada com base nas seguintes etapas sequenciais: acesso às referências bibliográficas de todos os artigos do $\mathrm{PB}$ e seleção das referências com título alinhado ao tema de pesquisa.
$\mathrm{Na}$ análise das referências bibliográficas do $\mathrm{PB}$, o periódico em destaque se altera, quando comparado ao periódico do PB (Figura 7).

Figura 7 - Periódicos relevantes nas referências bibliográficas do PB

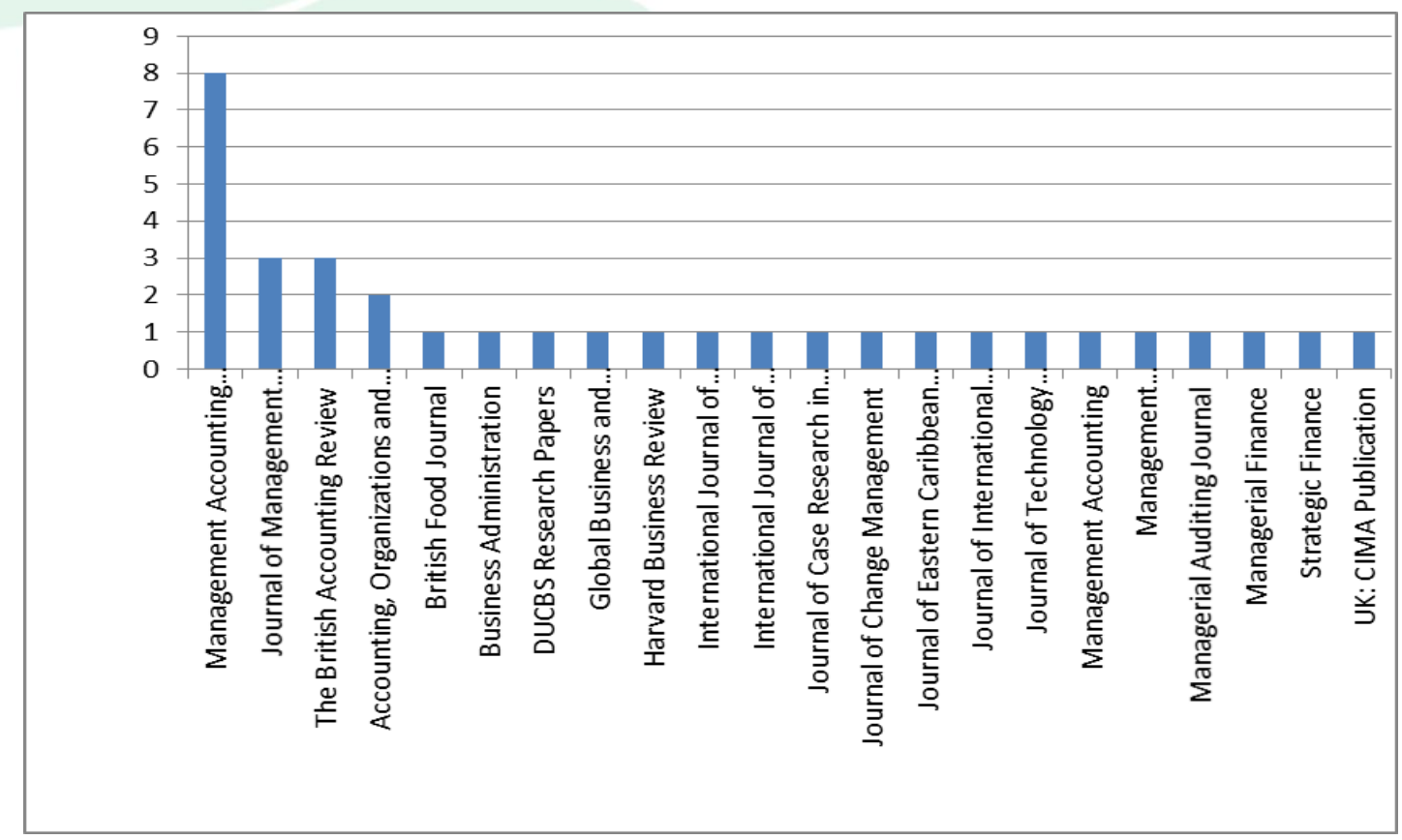

Fonte: Elaborado pelos autores. 
Nas referências do $\mathrm{PB}$, alinhadas ao tema pesquisado, os periódicos de maior destaque são: Management Accounting Research (23,5\%), Journal of Management Accounting Research (8,8\%), The British Accounting Review $(8,8 \%)$ e Accounting, Organizations and Society $(5,9 \%)$. Todas as revistas com maior representatividade das referências bibliográficas do $\mathrm{PB}$ possuem ligação direta com a Contabilidade e com os temas pesquisados.

\subsection{Artigos relevantes no Portfólio Bibliográfico}

O PB possui 16 artigos cuja forma de medição da relevância escolhida foi pela identificação do número de vezes em que cada artigo foi citado, utilizando a ferramenta Zotero®, a qual pesquisa as citações pelo Google Scholar ${ }^{\circledR}$. Na Figura 8, pode-se visualizar que o artigo com maior número de citações chegou a 400, sendo acompanhado por outros dois com representatividade de 250 e 277 citações.

Figura 8 - Artigos com representatividade no PB

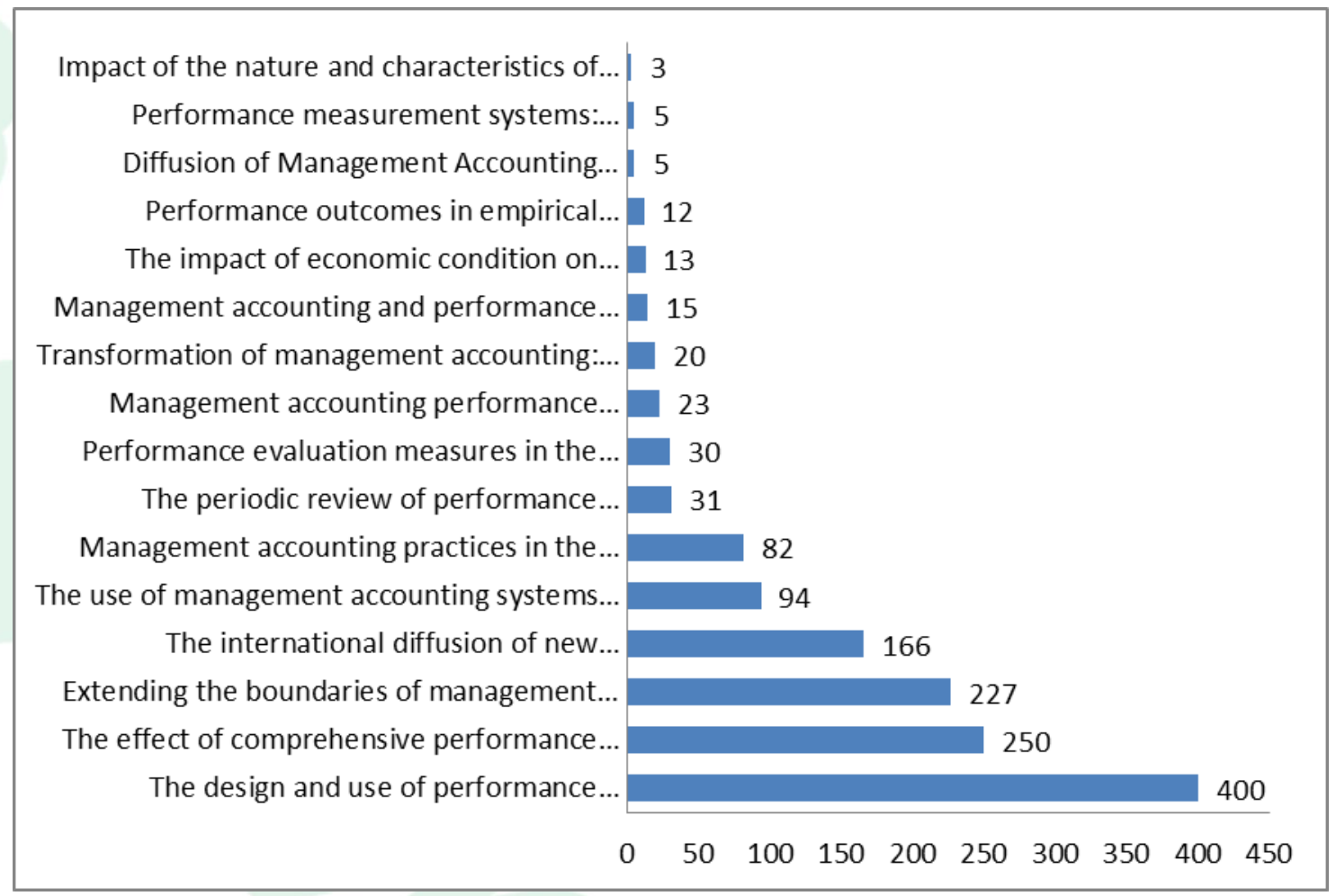

Fonte: Elaborado pelos autores.

Esses três artigos representam mais de $60 \%$ do total de citações de todo o PB. O artigo mais citado foi publicado, em 2008, por Aldónio Ferreira e David Otley; portanto, o fato de ele ser o mais citado, mesmo não sendo o mais antigo, indica que é relevante para a área.

\begin{abstract}
4.4 Autores relevantes no Portfólio Bibliográfico e nas suas referências bibliográficas

Com base na análise do PB, foram identificados 21 autores, um número relativamente pequeno, visto que o $\mathrm{PB}$ contém 16 artigos, o que significa que cada artigo possui, em média, 1,3 autores. O Quadro 1 apresenta todos os autores do PB.
\end{abstract}

Quadro 1 - Autores do PB

\begin{tabular}{|c|c|c|}
\hline A. Gunasekaran & Hussain, Md M. & Luther, R. \\
\hline Abdel-Kader, M. & Ismail, T. H. & Mia, L. \\
\hline Bremser, W. G. & Jerman, M. & Mohamed, E. \\
\hline Deshmukh, A. & Joshi, P. L. & Nita, B. \\
\hline Ferreira, A. & Kavčić, S., M. \\
\hline Hall, M. & Kihn, L. A. & Otley, D. \\
\hline Henri, J. F. & Kumar, R. & Patiar, A. \\
\hline
\end{tabular}

Fonte: Elaborado pelos autores. 
Foram analisados os autores que são relevantes para o $\mathrm{PB}$ e para as referências bibliográficas do $\mathrm{PB}$. No $\mathrm{PB}$, os autores mais relevantes são Md. Mostaque Hussain, professor da University of Vaasa e participante do Strategic Management Accounting Research Unit, com quatro publicações; David Otley, professor da Lancaster
University e membro da Associate Dean for Finance \& Resources, com duas publicações; e Prem Lal Joshi, professor da Multimedia University, na Faculty of Management, com duas publicações.

A Figura 9 apresenta a quantidade de publicações de cada autor do PB.

Figura 9 - Publicações por autor

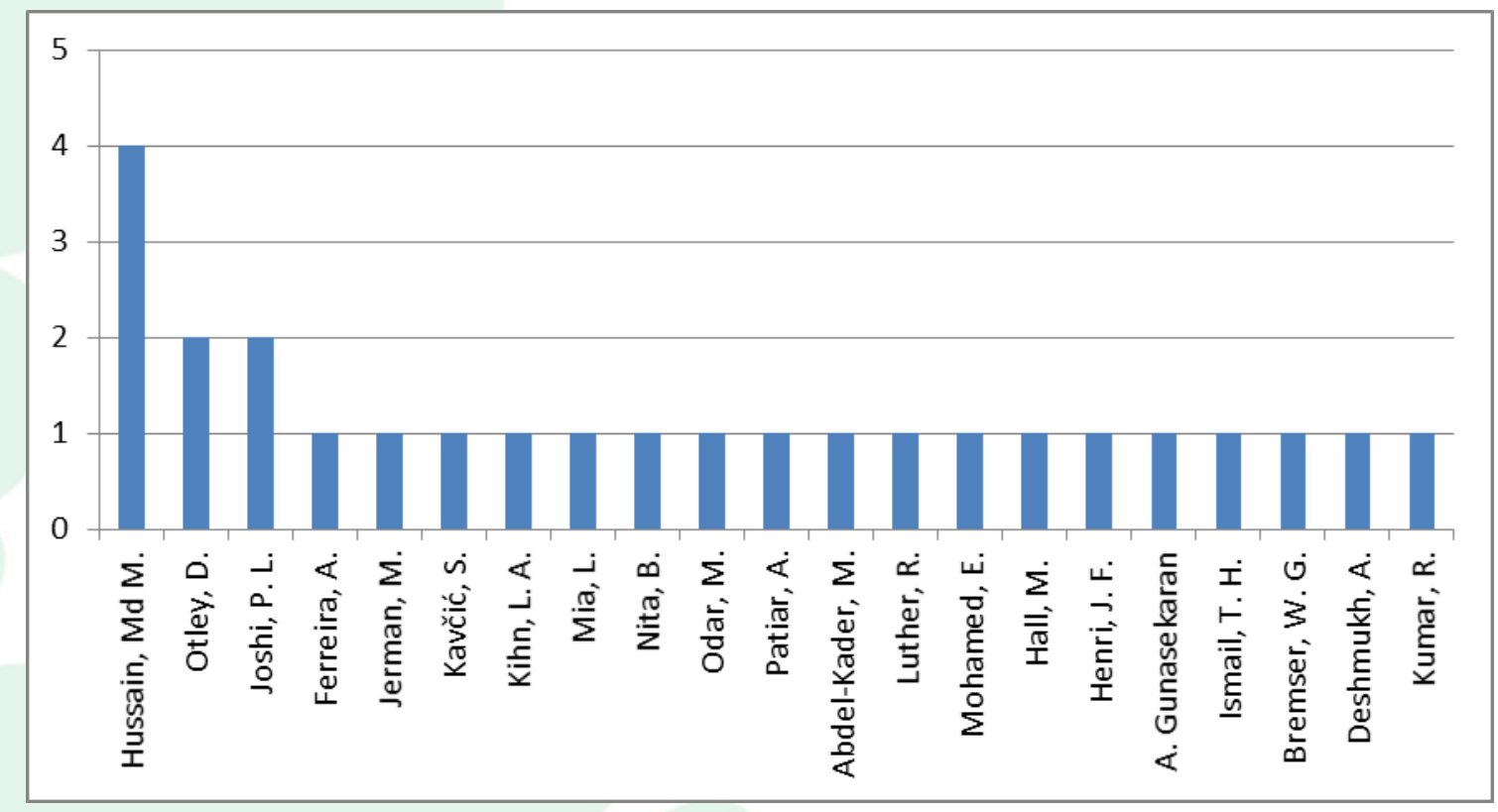

Fonte: Elaborado pelos autores.

Os quatro artigos publicados pelo autor de destaque do PB estão relacionados com o setor bancário e principalmente com a utilização de medidas não financeiras na Avaliação de Desempenho.

A identificação dos autores mais relevantes, por meio da análise das referências bibliográficas do PB, foi feita sem a utilização de software e realizada com base nas seguintes etapas sequenciais: acesso às referências bibliográficas de todos os artigos do PB e seleção das referências com título alinhado ao tema de pesquisa.

Em relação aos artigos das referências do PB, a análise trouxe um novo autor com maior relevância e outros dois que já foram vistos na análise dos artigos do PB. A Figura 10 apresenta a quantidade de publicação por autor dentre os autores das referências bibliográficas do PB. 
Avaliação de Desempenho na Contabilidade Gerencial: Aplicação do Processo Proknow-C para Geração de Conhecimento

Figura 10 - Publicações por autor das referências do PB

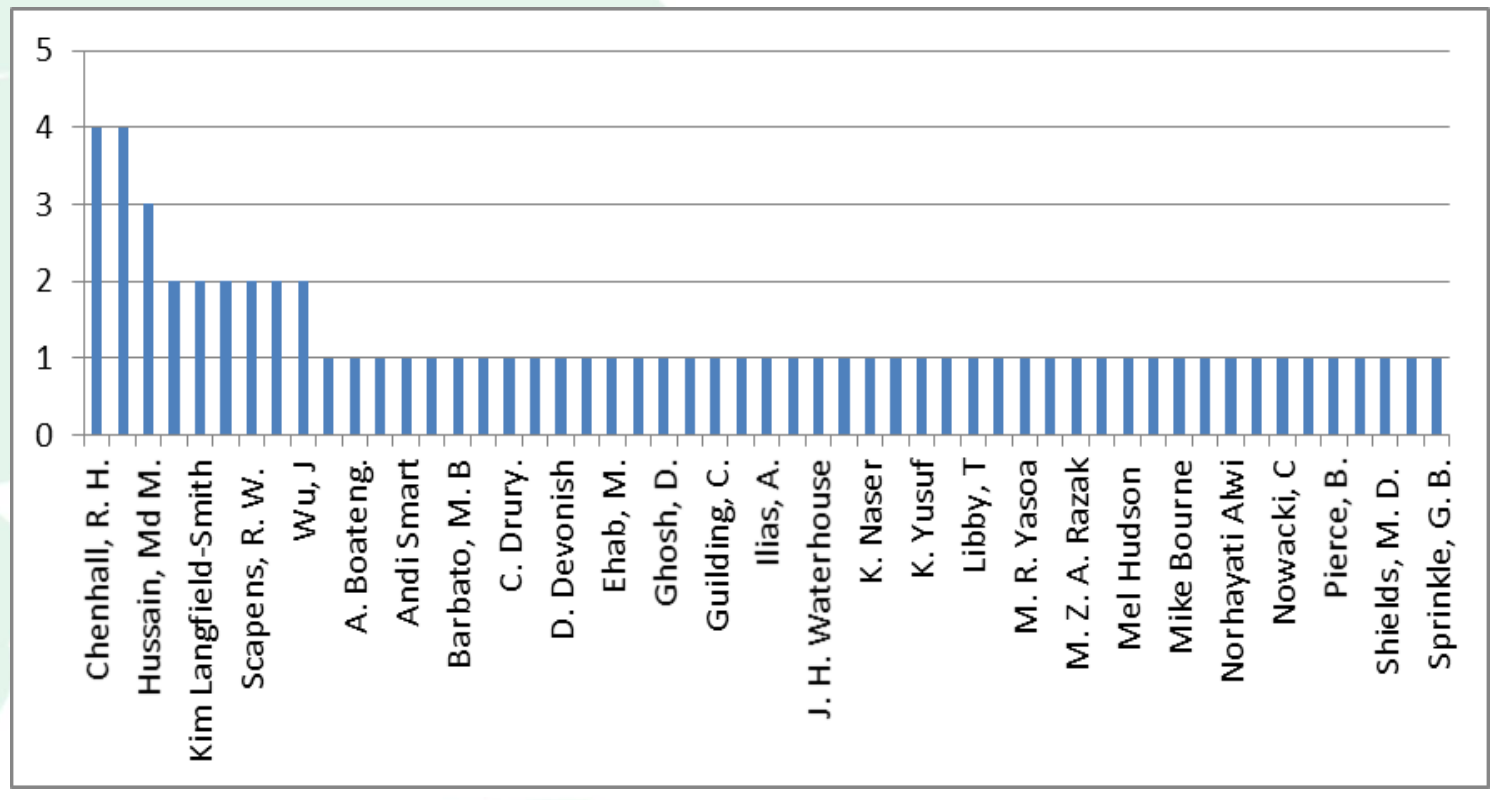

Fonte: Elaborado pelos autores.

Nas referências do PB, dois autores tiveram quatro publicações, e um autor, três publicações. Com quatro publicações, estão os autores Robert Chenhall e David Otley; e com três publicações, o autor Md. Mostaque Hussain. Robert Chenhal é professor na Monash University, no Departament of Accounting, e pesquisa na área de Contabilidade Gerencial. Observase uma semelhança entre os autores mais relevantes no $\mathrm{PB}$ e nas referências bibliográficas no $\mathrm{PB}$, sendo acrescentado apenas Robert Chenhall que não aparece no PB provavelmente devido aos anos de suas publicações.

4.5 Teorias em que os processos de avaliação de desempenho estão alicerçados
A análise das teorias foi feita com base na leitura integral das pesquisas selecionadas e nas definições apresentadas na metodologia.

No Quadro 2, observa-se que a maior parte dos estudos do PB utilizou como base a teoria da contingência. As medidas de desempenho e o sistema de medição utilizados não podem ser iguais para qualquer empresa, visto que cada uma possui características e diversidade em relação a outra. Portanto, o sistema de medição deverá levar em conta as particularidades do ramo em que cada organização atua. Dessa forma, cada empresa deve avaliar quais as medidas são mais adequadas às suas necessidades.

Quadro 2 - Teorias utilizadas

\begin{tabular}{|l|c|}
\multicolumn{1}{|c|}{ TÍTULO } & TEORIA \\
\hline $\begin{array}{l}\text { Diffusion of Management Accounting Practices in Gulf Cooperation } \\
\text { Council Countries }\end{array}$ & Cognitiva e processamento de informações \\
\hline $\begin{array}{l}\text { Extending the boundaries of management accounting research: } \\
\text { Developing systems for performance management }\end{array}$ & Contingência \\
\hline $\begin{array}{l}\text { Impact of the nature and characteristics of organizations on nonfinancial } \\
\text { performance measurement: The case of financial services industry }\end{array}$ & Contingência \\
\hline $\begin{array}{l}\text { Management accounting and performance measures in Japanese banks } \\
\text { Management accounting performance measurement systems in Swedish } \\
\text { banks. }\end{array}$ & Contingência de metas \\
\hline $\begin{array}{l}\text { Management accounting practices in the British food and drinks industry } \\
\text { Performance evaluation measures in the private sector: Egyptian practices }\end{array}$ & Definição de metas \\
\hline $\begin{array}{l}\text { Performance measurement systems: Empirical evidence from Slovenia. } \\
\text { Performance outcomes in empirical management accounting research: }\end{array}$ & Contingência \\
\hline
\end{tabular}


Avaliação de Desempenho na Contabilidade Gerencial: Aplicação do Processo Proknow-C para Geração de Conhecimento

\begin{tabular}{|l|c|}
\hline $\begin{array}{l}\text { The design and use of performance management systems: An extended } \\
\text { framework for analysis. }\end{array}$ & Contingência \\
\hline $\begin{array}{l}\text { The effect of comprehensive performance measurement systems on role } \\
\text { clarity, psychological empowerment and managerial performance }\end{array}$ & Cognitiva e processamento de informações \\
\hline $\begin{array}{l}\text { The impact of economic condition on management accounting } \\
\text { performance measures: experience with banks. }\end{array}$ & Contingência \\
\hline $\begin{array}{l}\text { The international diffusion of new management accounting practices: The } \\
\text { case of India }\end{array}$ & Cognitiva e processamento de informações \\
\hline $\begin{array}{l}\text { The periodic review of performance indicators: An empirical investigation } \\
\text { of the dynamism of performance measurement systems }\end{array}$ & Contingência \\
\hline $\begin{array}{l}\text { The use of management accounting systems in hotels: An exploratory study } \\
\text { Transformation of management accounting: From management control to } \\
\text { performance management. }\end{array}$ & Contingência \\
\hline
\end{tabular}

Fonte: Elaborado pelos autores.

Outras duas teorias identificadas foram a cognitiva e processamento de informações e a de definição de metas. Ambas as teorias se relacionam ao comportamento dos seres humanos quanto às medidas de avaliação utilizadas. Apesar de estarem em menor número entre os artigos do $\mathrm{PB}$, essas teorias revelam que os estudos têm levado em conta aspectos relacionados a comportamento quando se trata de avaliação de desempenho, já que as empresas são constituídas de pessoas e seu desempenho depende também da forma como se comportam. Dessa forma, a elaboração de pesquisas com foco nessas teorias tornase interessante ao analisar o comportamento das pessoas frente às medidas de desempenho e as metas utilizadas pelas entidades.

Em relação às teorias encontradas nas pesquisas no $\mathrm{PB}$, essas estão bem enraizadas e vinculadas aos resultados da aplicação de sistemas de avaliação de desempenho. Observou-se também que no PB não foram encontradas todas as teorias, nesse caso. Há ainda lacunas em termos de expansão das pesquisas com enfoque em outras teorias, como, por exemplo, a teoria da agência, visando à redução da assimetria informacional.

\subsection{Caminhos para a avaliação de desempenho}

Com base no Quadro 3, observou-se que, nas empresas onde foram aplicados os estudos, a maioria utilizava as variáveis financeiras e, ainda, não analisava quais as variáveis a serem utilizadas para a sua empresa, utilizando modelos estáticos. Nesses estudos, sugeriu-se que essas variáveis fossem ampliadas, utilizando as não financeiras e que elas deveriam ser dinâmicas, corroborando a teoria da contingência, para que cada empresa avalie as variáveis que serão mais úteis para a sua $\mathrm{AD}$. Isso auxilia as empresas a focarem mais na estratégia, já que variáveis que são genéricas, às vezes, podem influenciar para caminhos contrários àqueles definidos pela empresa. Portanto, as variáveis a serem utilizadas na $\mathrm{AD}$ devem estar ligadas à estratégia empresarial.

Algumas pesquisas demonstraram utilização da $\mathrm{AD}$ com foco na gestão, de forma mais ampla e mais eficaz quanto ao atingimento dos objetivos para os quais ela foi implementada, não apenas utilizando a avaliação de desempenho para a medição.

Quadro 3 - Caminhos para a AD

\begin{tabular}{|l|c|c|c|c|}
\hline \multicolumn{1}{|c|}{ Título } & $\begin{array}{c}\text { Do operacional } \\
\text { para o estratégico }\end{array}$ & $\begin{array}{c}\text { Da mensuração } \\
\text { para a gestão }\end{array}$ & $\begin{array}{c}\text { Do estático para } \\
\text { o dinâmico }\end{array}$ & $\begin{array}{c}\text { Do acionista } \\
\text { para os } \\
\text { usuários }\end{array}$ \\
\hline $\begin{array}{l}\text { Diffusion of Management Accounting } \\
\text { Practices in Gulf Cooperation Council } \\
\text { Countries }\end{array}$ & & $\mathrm{X}$ & & \\
\hline $\begin{array}{l}\text { Extending the boundaries of management } \\
\text { accounting research: Developing systems } \\
\text { for performance management }\end{array}$ & $\mathrm{X}$ & $\mathrm{X}$ & & \\
\hline $\begin{array}{l}\text { Impact of the nature and characteristics of } \\
\text { organizations on nonfinancial performance } \\
\text { measurement: The case of financial } \\
\text { services industry }\end{array}$ & $\mathrm{X}$ & & & \\
\hline $\begin{array}{l}\text { Management accounting and performance } \\
\text { measures in Japanese banks }\end{array}$ & $\mathrm{X}$ & & $\mathrm{X}$ & \\
\hline Management accounting performance & & & $\mathrm{X}$ & \\
\hline
\end{tabular}




\begin{tabular}{|l|c|c|c|c|}
\hline $\begin{array}{l}\text { measurement systems in Swedish banks. } \\
\text { Management accounting practices in the } \\
\text { British food and drinks industry }\end{array}$ & $\mathrm{X}$ & & & \\
\hline $\begin{array}{l}\text { Performance evaluation measures in the } \\
\text { private sector: Egyptian practices }\end{array}$ & $\mathrm{X}$ & $\mathrm{X}$ & $\mathrm{X}$ & \\
\hline $\begin{array}{l}\text { Performance measurement systems: } \\
\text { Empirical evidence from Slovenia. }\end{array}$ & $\mathrm{X}$ & & $\mathrm{X}$ & \\
\hline $\begin{array}{l}\text { Performance outcomes in empirical } \\
\text { management accounting research: Recent } \\
\text { developments and implications for future } \\
\text { research }\end{array}$ & $\mathrm{X}$ & & & \\
\hline $\begin{array}{l}\text { The design and use of performance } \\
\text { management systems: An extended } \\
\text { framework for analysis. }\end{array}$ & & $\mathrm{X}$ & & \\
\hline $\begin{array}{l}\text { The effect of comprehensive performance } \\
\text { measurement systems on role clarity, } \\
\text { psychological empowerment and } \\
\text { managerial performance }\end{array}$ & & $\mathrm{X}$ & & \\
\hline $\begin{array}{l}\text { The impact of economic condition on } \\
\text { management accounting performance } \\
\text { measures: experience with banks. }\end{array}$ & & $\mathrm{X}$ & $\mathrm{X}$ & \\
\hline $\begin{array}{l}\text { The international diffusion of new } \\
\text { management accounting practices: The } \\
\text { case of India }\end{array}$ & $\mathrm{X}$ & $\mathrm{X}$ & $\mathrm{X}$ & \\
\hline $\begin{array}{l}\text { The periodic review of performance } \\
\text { indicators: An empirical investigation of } \\
\text { the dynamism of performance measurement } \\
\text { systems }\end{array}$ & & $\mathrm{X}$ & & \\
\hline $\begin{array}{l}\text { The use of management accounting systems } \\
\text { in hotels: An exploratory study }\end{array}$ & & & & \\
\hline $\begin{array}{l}\text { Transformation of management } \\
\text { accounting: From management control to } \\
\text { performance management. }\end{array}$ & $\mathrm{X}$ & & & \\
\hline
\end{tabular}

Fonte: Elaborado pelos autores.

Pode-se observar que nenhum dos estudos do PB utilizou a avaliação de desempenho tendo uma visão que vai além do acionista, mais voltada para os stakeholders. Isso se dá pela utilização da AD apenas para interesse interno da empresa, com o foco na obtenção de resultados, já que as empresas normalmente utilizavam apenas variáveis financeiras na $\mathrm{AD}$. Esse fato representa uma lacuna de pesquisa para futuros trabalhos, dado que tal enfoque torna-se atraente para os interesses das empresas, já que elas também devem focar todas as partes interessadas.

De forma geral, as pesquisas do PB indicam uma tendência em estudos com caminhos de $\mathrm{AD}$ mais voltados para as características de cada empresa e focando na sua estratégia, não apenas utilizando a avaliação de desempenho como mera medição.

\subsection{Contribuições da pesquisa para o conhecimento acadêmico}

Entre os achados, identifica-se que a área tem sido pesquisada por autores que são atuantes na Contabilidade Gerencial, portanto possuem carreira ligada à área em que pesquisam. Além disso, observouse que vários estudos estão indo para além de questões financeiras, dando foco maior a questões não financeiras na avaliação de desempenho, visando ao desenvolvimento da organização para além do financeiro e com foco na medição além do financeiro para alcançar melhores resultados.

Observou-se ainda que, para o fragmento da literatura pesquisado, as pesquisas demonstraram que a avaliação de desempenho vem sendo pensada com foco um pouco mais voltado para a questão social, para a forma como as pessoas se comportam perante as medições utilizadas.

Outro destaque, no que tange aos achados da pesquisa, se dá em relação ao foco da avaliação de desempenho, onde ela tem foco mais voltado para a gestão, ligando-se à estratégia da empresa, não apenas a utilizando para medição de desempenho.

Adicionalmente, com o desenvolvimento da pesquisa associado às noções apresentadas no referencial teórico, os pesquisadores identificaram oportunidades de pesquisa sob o olhar das implicações gerenciais, apresentadas no Quadro 4. 
Quadro 4 - Oportunidades práticas para o fragmento da literatura da avaliação de desempenho na contabilidade gerencial

\section{DESAFIOS PARA OS CONTADORES GERENCIAIS}

Os contadores gerenciais necessitam manter uma ligação com aqueles que estudam e constroem a estratégia da organização para então construírem e ajustarem os sistemas de avaliação de desempenho a situação real da organização.

Os contadores gerenciais, considerando que a contabilidade, em sua essência é descrita como a linguagem dos negócios, devem buscar acompanhar às áreas-chave da organização para então adaptar o sistema de avaliação de desempenho as práticas organizacionais e as necessidades de um ambiente em rápida mutação.

Os contadores gerenciais necessitam ter em mente que o sistema de avaliação de desempenho é um instrumento capaz de "influenciar o comportamento" das pessoas; sendo assim, devem concebê-lo como um mecanismo de agregar os diversos stakeholders.

Os contadores gerencias necessitam preocupar-se em desenvolver sistemas de avaliação de desempenho ad hoc suficientemente abrangente que identifique e mensure as situações operacionais, econômicas e financeiras sendo capaz de oferecer informação útil à gestão organizacional.

Fonte: Dados da pesquisa.

As informações evidenciadas no Quadro 4 podem ser úteis para os pesquisadores, responsáveis por ampliar os horizontes do conhecimento e também para os contadores gerenciais, responsáveis pela melhoria do desempenho organizacional.

\section{CONSIDERAÇÕES FINAIS}

O presente trabalho teve por objetivo fazer uma análise das características das pesquisas científicas internacionais relacionadas ao fragmento da literatura sobre a utilização da Avaliação de Desempenho na Contabilidade Gerencial, tendo como meta a geração de conhecimento e identificação de lacunas para o apontamento de possibilidade de pesquisas futuras. A operacionalização da ferramenta ProKnow-C permitiu que o objetivo fosse alcançado, selecionando-se, com base nessa ferramenta, um Portfólio Bibliográfico (PB) composto por 16 artigos. Por meio desse PB, foi feita a análise bibliométrica, tendo como base as características básicas, os caminhos da avaliação de desempenho, bem como as teorias em que está alicerçada.

Com base na bibliometria, observou-se que o periódico Transformations in Business and Economics foi o mais relevante no PB. Esse periódico está ligado a pesquisas em Economia e suas mudanças e teve duas publicações do PB. Isso demonstra que os estudos relacionados à avaliação de desempenho na contabilidade gerencial não se limitam a publicações em revistas com ligação direta à Contabilidade, mas também àquelas ligadas à Economia de forma geral. Em relação aos autores, identificou-se que as pesquisas são realizadas por aqueles que possuem trajetória no tema estudado. $\mathrm{O}$ autor de destaque no PB foi $\mathrm{Md}$. Mostaque Hussain, professor e pesquisador na área de contabilidade gerencial.
Em relação à análise das teorias, identificou-se que a maior parte dos estudos $(62,5 \%)$ utilizou como base a teoria da contingência, demonstrando preocupação do pesquisador quanto à adaptação das medidas de desempenho às empresas, visto que elas devem ser dinâmicas e ser utilizadas de acordo com as necessidades empresariais. Além disso, observou-se que inexistem trabalhos que utilizam as teorias dos stakeholders e a teoria da agência, o que demonstra que a avaliação de desempenho não tem sido utilizada para a redução de assimetria informacional e não tem adicionado às suas preocupações a visão das suas partes interessadas.

No que diz respeito aos caminhos da avaliação de desempenho, os resultados demonstraram que os autores sugeriram o caminho da $\mathrm{AD}$ do estático para o dinâmico em vários trabalhos, que vai ao encontro da utilização da teoria da contingência, demonstrando grande preocupação no uso de indicadores de desempenho que estejam de acordo com as necessidades de cada empresa e que representem os interesses definidos na estratégia empresarial.

Dessa forma, algumas lacunas de pesquisa foram identificadas, tais como: inexistência de pesquisas que tenham como foco a teoria da agência e a teoria dos stakeholders; inexistência de pesquisas tendo como foco o caminho da Avaliação de Desempenho ampliando para os stakeholders; inexistência de pesquisas que combinem a teoria dos stakeholders e o caminho da avaliação de desempenho que busca adicionar interesses relacionados aos stakeholders.

Com a finalidade de que sejam alcançados avanços na área onde a pesquisa foi realizada, são sugeridos trabalhos no sentido de que se ampliem estudos que englobem os interesses de todas as partes interessadas pelo uso do sistema de avaliação de desempenho, sendo utilizada a teoria dos stakeholders ou o caminho da avaliação de desempenho que leva aos 
interesses dos usuários, de forma que sejam ampliadas as informações a serem geradas pelo sistema de avaliação de desempenho, podendo, ainda, ser feita a combinação entre a teoria dos stakeholders e tal caminho da avaliação de desempenho.

As limitações da presente pesquisa são: (i) restrição quanto ao idioma do Portfólio Bibliográfico, onde foram selecionadas apenas pesquisas na língua inglesa, com base em publicações em revistas científicas buscadas nas bases de dados da CAPES, com disponibilidade gratuita na internet; (ii) definição das características que foram analisadas pelos pesquisadores, principalmente as variáveis de teorias e caminhos da $\mathrm{AD}$, que, associados às noções apresentadas no referencial teórico, permitiram a identificação de oportunidades futuras de pesquisas; e, (iii) utilização de julgamento e interpretação por parte dos autores quanto à análise dos artigos do PB em relação às variáveis investigadas. Dessa forma, a interpretação apresentada nesta pesquisa pode ser diferente daquelas apresentadas pelos autores originais dos estudos.

Por fim, sugere-se para futuras pesquisas: (i) ampliação da presente pesquisa a outras bases de dados, outros idiomas e outras características, além de eliminar a delimitação temporal; (ii) utilização de outras variáveis de análise; (iii) a continuidade desta investigação com o desenvolvimento da etapa 'análise sistêmica' por meio do ProKnow-C, com base no estabelecimento da afiliação teórica dos pesquisadores; e, (iv) realização de pesquisas que tenham por objetivo eliminar as lacunas de pesquisas identificadas e apontadas.

\section{REFERÊNCIAS}

Abdel-Kader, M., \& Luther, R. (2006). Management accounting practices in the British food and drinks industry. British Food Journal, 108(5), 336-357.

Bititci, U., Garengo, P., Dörfler, V., \& Nudurupati, S. (2012). Performance Measurement: Challenges for Tomorrow. International Journal of Management Reviews, 14, 305-327.

Castro, C. D. M. (1977). A prática da pesquisa. McGraw-Hill.

Creswell, J. W. (2014), Research Design: Qualitative, Quantitative, and Mixed Methods Approaches, 4th ed., Sage Publications, CA.

Donaldson, T., \& Preston, L. E. (1995). The stakeholder theory of the corporation: Concepts, evidence, and implications. Academy of management Review, 20(1), 65-91.

Dutra, A., Ripoll-Feliu, V. M., Fillol, A. G., Ensslin, S. R., \& Ensslin, L. (2015). The construction of knowledge from the scientific literature about the theme seaport performance evaluation. International Journal of Productivity and Performance Management, 64(2), 243-269.

Ensslin, L., Ensslin, S. R., Lacerda, R. R. O., \& Tasca, J. E. (2010). ProKnow-C, Knowledge Development Process-Constructivist. Processo técnico com patente de registro pendente junto ao INPI. Brasil.

Ensslin, L., Ensslin, S. R., \& Pinto, H. D. M. (2013). Processo de investigação e Análise bibliométrica: Avaliação da Qualidade dos Serviços Bancários. Revista de Administração Contemporânea, 17(3), 325-349.

Ensslin, S. R., Ensslin, L., Imlau, J. M., \& Chaves, L. C. (2014). Processo de mapeamento das publicações científicas de um tema: portfólio bibliográfico e análise bibliométrica sobre avaliação de desempenho de cooperativas de produção agropecuária. Revista de Economia $e$ Sociologia Rural, 52(3), 587-608.

Ferreira, A., \& Otley, D. (2005). The Design and Use of Management Control Systems: An Extended Framework for Analysis. AFAANZ Annual Conference, BAA Annual Conference, of the 2nd Conference on Performance Measurement and Management Control, (October), 1-54.

Franco-Santos, M., Kennerley, M., Micheli, P., Martinez, V., Mason, S., Marr, B., Gray, D., \& Neely. A. (2007). Towards a Definition of a Business Performance Measurement System. International Journal of Operations and Production Management, 27(8), 784-801.

Franco-Santos, M., Lucianetti, L., \& Bourne, M. (2012). Contemporary performance measurement systems: A review of their consequences and a framework for research. Management Accounting Research, 23(2), 79-119.

Hall, M. (2008). The effect of comprehensive performance measurement systems on role clarity, psychological empowerment and managerial performance. Accounting, Organizations and Society, 33(2-3), 141-163.

Henri, J.-F. (2010). The Periodic Review of Performance Indicators: An Empirical Investigation of the Dynamism of Performance Measurement Systems. European Accounting Review, 19(1), 7396.

Hussain, M. M. (2003). The impact of economic condition on management accounting performance measures: experience with banks. Managerial Finance, 29(2/3), 23-41. 
Hussain, M. M. (2005). Management accounting performance measurement systems in Swedish banks. European Business Review, 17(6), 566-589.

Hussain, M. M., \& Gunasekaran, A. (2002). Management accounting and performance measures in Japanese banks. Managing Service Quality, 12(4), 232-245.

Ismail, T. H. (2007). Performance evaluation measures in the private sector: Egyptian practice. Managerial Auditing Journal, 22(5), 503-513.

Joshi, P. L. (2001). The international diffusion of new management accounting practices: the case of India. Journal of International Accounting, Auditing and Taxation, 10, 85-109.

Joshi, P. L., Bremser, W. G., Deshmukh, A., \& Kumar, R. (2011). Diffusion of Management Accounting Practices in Gulf Cooperation Council Countries. Accounting Perspectives, 10(1), 23-53.

Kihn, L. A. (2010). Performance outcomes in empirical management accounting research: Recent developments and implications for future research. International Journal of Productivity and Performance Management, 59(5), 468-492.

Kruger, S.D., Petri, S. M., Ensslin, S. R., \& Matos, L. dos S. (2015). Performance evaluation of poultry production sustainability: international mapping regarding this issue.Custos e @gronegócio on line, 11(4), 124-153.

Melnyk, S. A., Bititci, U., Platts, K., Tobias, J., \& Andersen, B. (2014). Is performance measurement and management fit for the future? Management Accounting Research, 25(2), 173-186.

Mia, L., \& Patiar, A. (2001). The use of management accounting systems in hotels: an exploratory study. International Journal of Hospitality Management,20(2), 111-128.

Mohamed, E. (2005). Impact of the nature \& characteristics of organizations on non- financial performance measurement: the case of financial services industry. Journal of Case Research in Business and Economics, 1-17.

Neely, A., Gregory, M., \& Platts, K. (1995). Performance measurement system design - A literature review and research agenda. International Journal of Operations \& Production Management, 15(4), 80-116.
Neely, A. (1999). The performance measurement revolution: why now and what next? International Journal of Operations \& Production Management, 19(2), 205-228.

Nita, B. (2008). Transformation of management accounting: From management control to performance management. Transformations in Business and Economics, 7(3), 53-64.

Nudurupati, S. S., Bititci, U. S., Kumar, V., \& Chan, F. T. S. (2011) State of the art literature review on performance measurement. Computers \& Industrial Engineering, 60(2), p. 279-290.

Odar, M., Kavčič, S., \& Jerman, M. (2012). Performance measurement systems: Empirical evidence from Slovenia. Economic ResearchEkonomska Istraživanja, 25(2), 445-464.

Otley, D. (2001). Extending the boundaries of management accounting research: developing systems for performance management. The British Accounting Review, 33(3), 243-261.

Roy, B. (1990). Decision-aid and decision-making. European Journal of Operational Research, v. 45, n. $2-3$, p. $324-331$.

Roy, B. (1993). Decision science or decision-aid science. European Journal of Operational Research, Vol. 66 No. 2, pp. 184-203.

Srimai, S., Radford, J., \& Wright, C. (2011). Evolutionary paths of performance measurement: an overview of its recent development. International Journal of Productivity and Performance Management, 60(7), 662-687.

Valmorbida, S., \& Ensslin, L. (2016). Construção de conhecimento sobre avaliação de desempenho para gestão organizacional: uma investigação nas pesquisas científicas internacionais. Revista Contemporânea de Contabilidade, 13(28), 123-148.

Waiczyk, C., \& Ensslin, S. R. (2013). Avaliação de produção científica de pesquisadores: mapeamento das publicações científicas. Revista Contemporânea de Contabilidade, 10(20), 97-112.

Yin, R. K. (2009), “Case study research: design and methods", 4th ed., Sage, Thousand Oaks, CA.

Yadav, N., Sushil, \& Sagar, M. (2014) Revisiting performance measurement and management: Deriving linkages with strategic management theories. International Journal of Business Performance Management, 15(2), 87-105. 